DOI: $10.2478 /$ lpts-2018-0018

\title{
SIMULATION OF SEISMIC EXPLOSION WAVES WITH UNDERGROUND PIPE INTERACTION
}

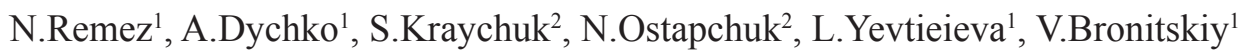 \\ ${ }^{1}$ Institute of Energy Saving and Energy Management, National \\ Technical University of Ukraine "Igor Sikorsky Kyiv Polytechnic Institute" \\ 37 Peremohy Ave., Kyiv, 03056, UKRAINE \\ ${ }^{2}$ Department of Economic Cybernetics, Rivne State University of Humanities \\ 12 Stepana Bandery Str., Rivne, 33000, UKRAINE
}

\begin{abstract}
The present paper provides numerical simulation of interaction of wave processes in the system "soil massif - underground pipeline" in explosion of charge on the surface of ground. Construction is considered in the framework of nonlinear theory of shells of Tymoshenko type. Soil is modelled by a solid porous multicomponent visco-plastic medium. The study establishes patterns of changes in stress-strain state of system depending on depth of pipeline laying and its diameter.
\end{abstract}

Keywords: distraction, explosion, numerical simulation, underground pipe

\section{INTRODUCTION}

Supply of oil, gas, drinking water, drainage is one of the necessary conditions for urbanised areas. Usually these benefits of civilization are transmitted and distributed through pipelines. At the same time, different variations of pipes are used in construction and for transfer of water, gas and oil through distributive systems. All these pipes are earthed in soil to protect them from adverse environmental factors and dynamic effects of various nature: earthquakes, explosions, vibrations from transport and working machines, diversions. But such loads on a pipeline as effect of weight of soil mass, fluid pressure, etc. are increased with earth.

Different factors, such as soil properties, intensity of soil fluctuations, internal pressure of pipe, its dimensions, including diameter and thickness of wall, parameters and nature of dynamic loads have a consistent effect on stability of underground pipelines [1]-[2]. Therefore, when calculating the stress-strain state, fluctuations of the pipeline-soil system should be considered. Its dynamic characteristics are different from the dynamic characteristics of the pipeline separated conditionally from soil environment.

Most studies of the dynamic effect on underground pipelines are devoted to impact of earthquakes and seismic waves of various nature [3]-[6]. 


\section{NUMERICAL SIMULATION}

The goal of the research is to determine the effect of explosive action of surface charge on underground pipeline. When modelling it is assumed that charge of explosives detonates on surface of soil. At the same time, an explosive wave propagates into soil massif with pipeline, located inside.

In the cylindrical coordinate system $r, z$ equations of motion of soil within the framework of mechanics of continuous medium have the form:

$$
\begin{aligned}
& \frac{\partial \sigma_{r r}}{\partial z}+\frac{\partial \tau_{r z}}{\partial r}+\frac{\tau_{r z}}{r}=\rho \frac{d u}{d t}, \\
& \frac{\partial \tau_{r z}}{\partial z}+\frac{\partial \sigma_{z z}}{\partial r}+\frac{\sigma_{z z}-\sigma_{\theta \theta}}{r}=\rho \frac{d w}{d t}, \\
& \frac{1}{V} \frac{d V}{d t}=\frac{\partial u}{\partial z}+\frac{\partial w}{\partial r}+\frac{w}{r}, \quad V=\frac{\rho_{0}}{\rho}, \\
& u=\frac{d z}{d t}, w=\frac{d r}{d t}, \quad \\
& \sigma_{z z}=S_{z z}-P, \sigma_{r r}=S_{r r}-P, \sigma_{r r}=S_{r r}-P, \\
& P=\frac{1}{3}\left(\sigma_{r r}+\sigma_{\theta \theta}+\sigma_{z z}\right),
\end{aligned}
$$

where $\sigma_{r r}, \sigma_{\theta \theta}, \sigma_{z z}, S_{r r}, S_{\theta \theta}, S_{z z}$ - components of tensor and deviator of stress tensors; $\tau_{r z}-$ tangential stress, $\tau_{r z}-$ initial and current density of medium, $t$ - time.

The soil is modelled by a solid porous multicomponent visco-plastic medium with a constant viscosity coefficient [7], and its equation of dynamic volume compression and discharge has the following form:

$$
\dot{\varepsilon}=\varphi(P, \varepsilon) \dot{P}-\frac{\alpha_{1} \lambda(P, \varepsilon)}{\eta} \psi(P, \varepsilon) .
$$

Functions included in equation (7) for loading and unloading $S_{i}$ are different and determined according to [7].

The condition of soil plasticity is the modified condition of Mises-Botkin [8].

The theory of shells of the Tymoshenko type and physical relations of differential plasticity theory with linear kinematic hardening are used to describe dynamic behaviour of the pipeline [9], [10]. Equations of fluctuations for a cylindrical shell have the form: 


$$
\begin{aligned}
& \frac{\partial T_{11}}{\partial x}=\rho h \frac{\partial^{2} u_{1}}{\partial t^{2}}, \\
& \frac{\partial \bar{T}_{13}}{\partial x}-\frac{T_{22}}{R}+P_{3}(x, t)=\rho h \frac{\partial^{2} u_{3}}{\partial t^{2}}, \\
& \frac{\partial M_{11}}{\partial x}-T_{13}+P_{3}(x, t)=\rho \frac{h^{3}}{12} \frac{\partial^{2} \phi_{1}}{\partial t^{2}} .
\end{aligned}
$$

Expressions for the values of forces-moments are the following:

$$
\begin{aligned}
& T_{11}=B_{11}\left(\varepsilon_{11}+v_{21} \varepsilon_{22}\right), \\
& T_{22}=B_{22}\left(\varepsilon_{22}+v_{12} \varepsilon_{11}\right), \\
& T_{13}=B_{13} \varepsilon_{13}, \quad M_{11}=D_{11} \kappa_{11},
\end{aligned}
$$

where

$$
\begin{aligned}
& \varepsilon_{11}=\frac{\partial u_{1}}{\partial x}+\frac{1}{2}\left[\theta_{1}\right]^{2}, \varepsilon_{22}=\frac{u_{3}}{R}, \varepsilon_{13}=\varphi_{1}+\theta_{1}, \theta_{1}=\frac{\partial u_{3}}{\partial x}, \kappa_{11}=\frac{\partial \varphi_{1}}{\partial x} ; \\
& B_{11}=\frac{E_{1} h}{1-v_{12} v_{21}}, B_{22}=\frac{E_{2} h}{1-v_{12} v_{21}}, B_{13}=G_{13} h, D_{11}=\frac{E_{1} h^{3}}{12\left(1-v_{12} v_{21}\right)} .
\end{aligned}
$$

In formulas (8)-(11), the following designations are taken: $\rho, h, R$ - density of material, thickness and radius of pipe; $u_{1}, u_{3}, \phi_{1}-$ components of generalised vector of displacements; $T_{11}, T_{13}, T_{22}, M_{11}$ - components of tensors of forces and moments; $P_{3}$ - pressure; $\varepsilon_{11}, \varepsilon_{22}, \varepsilon_{13}$ - components of deformation tensor; $E_{1}, E_{2}, v_{12}, v_{21}, G_{13}-$ elastic constants of pipeline material.

In the case of plastic deformations, relationships between corresponding deformations and stresses are written in the form of incremental theory of plasticity with the Mises condition.

conditions.

Equations (1)-(11) are supplemented by the corresponding initial and limit

\section{RESULTS AND DISCUSSION}

With the help of the finite elements method, modelling of soil environment, in which an underground gas pipeline is located, is carried out. For numerical simulation, a calculating grid of 9635 elements is constructed.

It is assumed that the pipeline, which is located in clay soil at a depth of 2.0$6.0 \mathrm{~m}$, is made of steel with the following physical and mechanical characteristics: 
yield limit $\mathrm{G}=240 \mathrm{~N} / \mathrm{m}^{2}$, Poisson coefficient $v=0.3$, elasticity modulus $E=240$ $\mathrm{N} / \mathrm{m}^{2}$, density $=7855 \mathrm{~kg} / \mathrm{m}^{3}$.

The explosion of charge of 10 kilograms of trotyl on a soil surface is considered. It corresponds to the minimum power of loaded charge, a bomb or a small rocket. Dependence of stress on time on the surface of the soil massif is shown in Fig. 1.

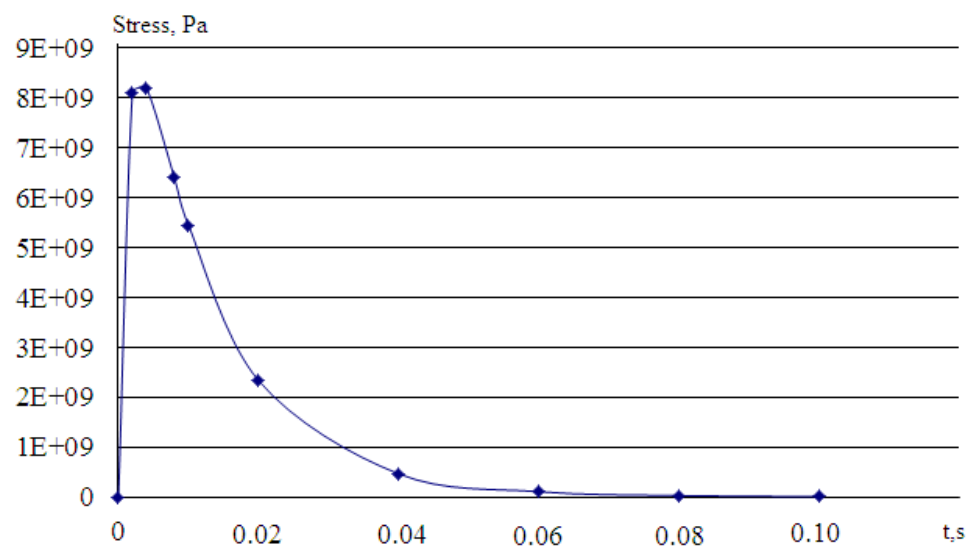

Fig. 1. Dependence of stress on time on the surface of the soil massif.

Isobars of average hydrostatic pressure (in $\mathrm{GPa}$ ) in plane at different moments of time $\mathrm{t}=1.0 \mathrm{~s}$ are presented in Fig. 2 .

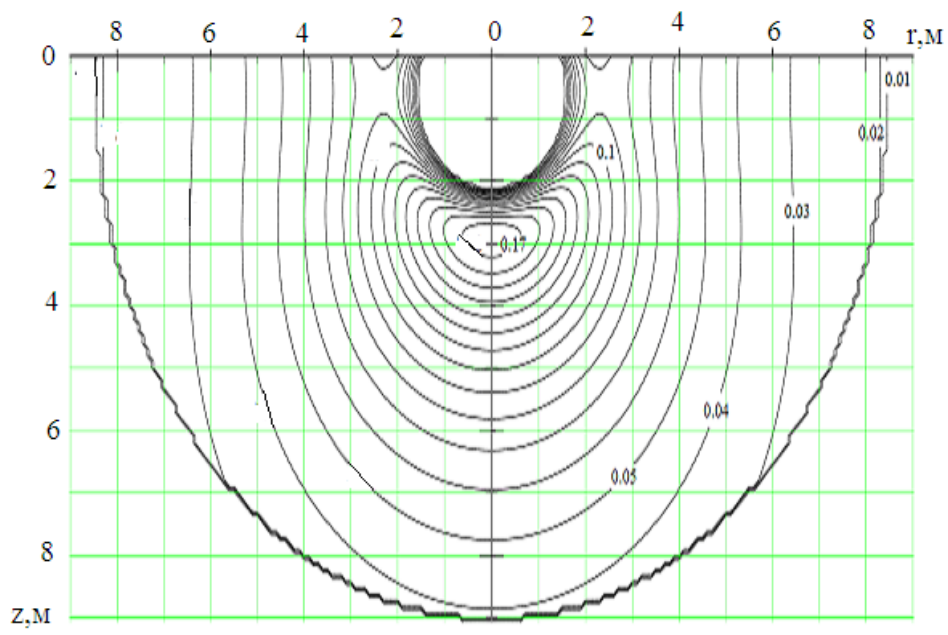

Fig. 2. Isobars of average hydrostatic pressure (in $\mathrm{GPa}$ ) in plane $\mathrm{rOz}$ at different moments of time $\mathrm{t}=1.0 \mathrm{~s}$.

It is shown in Fig. 2 that the field of isobars is a difficult depiction due to interaction of waves with different limits and angular points, and also between themselves. At the considered moment of time, the greatest load is achieved in gas cavity and in soil near it. 
The stress wave, spreading in soil, reaches the pipeline and causes deformation in these media (Fig. 3).

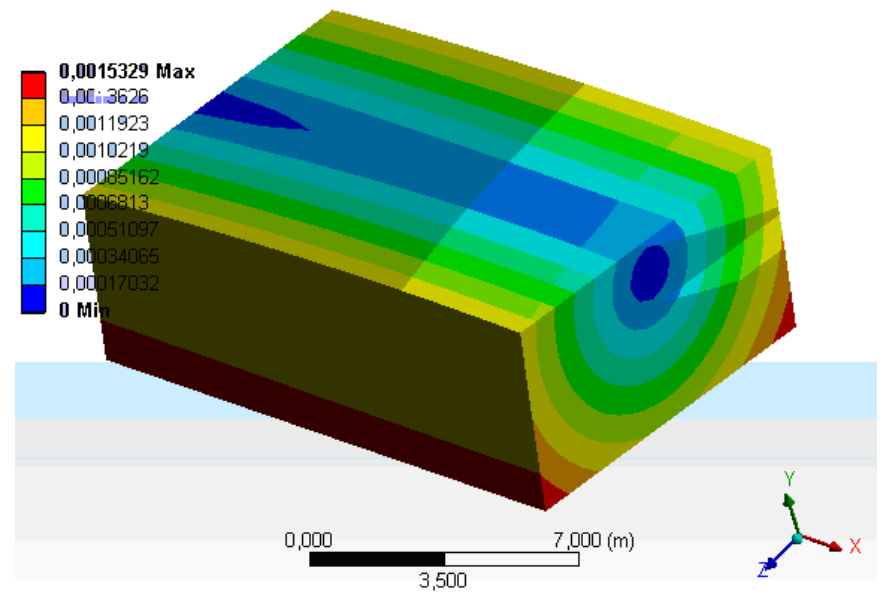

Fig. 3. Distribution of volumetric deformations in soil and pipelines.

Distribution of stresses in a steel pipe of $1.5 \mathrm{~m}$ in diameter at a laying depth of $5 \mathrm{~m}$ is shown in Fig. 4.
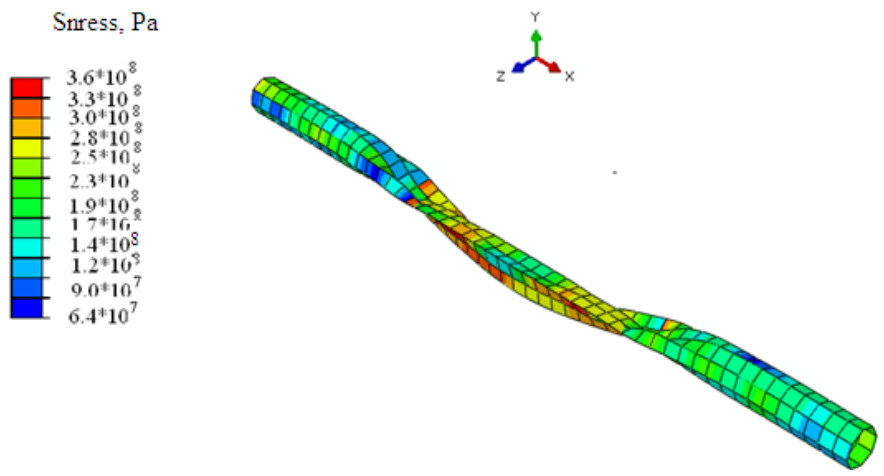

Fig. 4. Distribution of stresses in the steel pipe of $1.5 \mathrm{~m}$ in diameter at a laying depth of $5 \mathrm{~m}$.

It is seen from the figure that the maximum stress in the pipeline is reached at $360 \mathrm{MPa}$, which is significantly greater than the steel yield limit (240 MPa), especially in frontal surface of pipe; therefore, pipeline loses its bearing capacity and is destroyed.

Dependence of stress on pipeline from depth of its laying at different diameters of pipeline: $1-D=0.4 \mathrm{~m}, 2-\mathrm{D}=1.5 \mathrm{~m}$ is shown in Fig. 5 . It is established that with a decrease in diameter, the stress increases, and the pipe undergoes plastic deformation and loses its ability to work.

With an increase in depth of pipeline arrangement, there is a decrease in stresses, but the area of elastic deformations for a pipe with a diameter of $1.5 \mathrm{~m}$ starts at a depth of $6 \mathrm{~m}$, and with a diameter of $0.4 \mathrm{~m}$ - from a depth of $7 \mathrm{~m}$. 


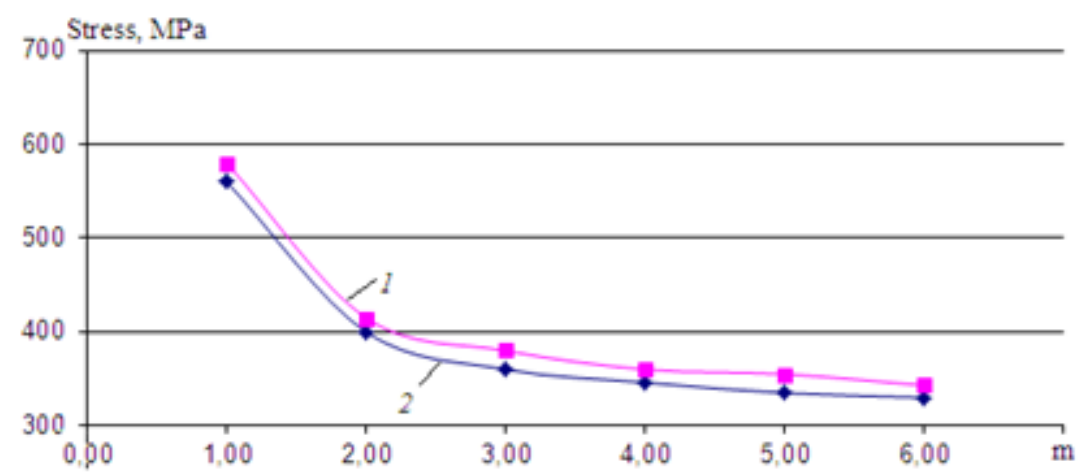

Fig. 5. Dependence of stress on pipeline from depth of its laying at different diameters of pipeline: $1-\mathrm{D}=0.4 \mathrm{~m}, 2-\mathrm{D}=1.5 \mathrm{~m}$.

Dependences of polynomial stresses on depth of laying the pipeline, which allow carrying out predictive calculations of durability of pipe under different dynamic loads, are obtained:

- for a pipe with a diameter of $1.5 \mathrm{~m}$ :

$\sigma=-5.92 y^{3}+78.04 y^{2}-337.76 y+882.00, P a ; R^{2}=0.991$,

- for a pipe with a diameter of $0.4 \mathrm{~m}$ :

$\sigma=1.94 y^{4}-33.47 y^{3}+211.66 y^{2}-591.51 y+990.83, P a ; R^{2}=0.9981$.

\section{CONCLUSIONS}

The present study has introduced the methodology of numerical solution to the problem of explosion of a charge of trotyl on the surface of a soil massif with a pipeline placed inside. It makes it possible to investigate regularities of variation of wave processes in heterogeneous "soil-pipeline" system.

The authors of the research have developed the mathematical model, algorithm and program for a numerical solution to the problem of dynamic change of stress-strain state by "soil massive-underground pipeline" system in explosion, of physical-mechanical characteristics of soil and pipeline material, as well as geometric dimensions of the last one (pipe diameter and thickness).

It has been established that with a decrease in diameter of pipeline the stress increases, and pipe undergoes plastic deformation and loses its efficiency. With an increase in depth of pipeline location, there is a decrease in stress; thus, the area of elastic deformations of a pipe with a diameter of $1.5 \mathrm{~m}$ begins with a depth of $6 \mathrm{~m}$, and for a diameter of $0.4 \mathrm{~m}$ - from a depth of $7 \mathrm{~m}$.

Polynomial dependences of stresses on depth of laying the pipeline, which allow carrying out predictive calculations of durability of pipe under different dynamic loading, have been obtained in the present research.

Results of the research can be used for determining the safe depth of laying the pipelines of various purposes when they are subject to dynamic shock loads. 


\section{REFERENCES}

1. Shemyakin, E.I. (1963). About waves of stresses in durable mountains rocks. PMTF. 3, 83-93.

2. Borovikov, V.A., \& Vanyagin I.V. (1976). To the calculation of stress wave parameters at explosion-prolonged charge in rocks. Explosive Affair, 76(33), 74-85.

3. Jeremy, I. (1978). Underground pipeline behaviour under seismic loading. In Division, A.G.E. (Ed.), Earthquake engineering and soil dynamics. New York, American Society of Civil Engineers.

4. Golbahar Haghighy, M. V., \& Agha Kuchak, E. A. (2006). Analysis of marine pipe lines subjected to the loading caused by propagation of seismic wave and fault displacement, Marine Engineering Magazine.

5. Leon, R. L., \& Wang, M. (1978). Performance of underground pipelines in earthquake, In Division, A. G. E. (Ed.), Earthquake engineering and soil dynamics. New York, American Society of Civil Engineers.

6. Remes, N. S., Ivanova, I. A., \& Demeschuk, N. S. (2014). Interaction of seismic waves with layered soil array and underground pipelines. Visnyk NTUU "KPI", series "Mining", 24, 27-34.

7. Luchko, I. A., Plaksii, V. A., \& Remez, N. S. (1964). Cylindrical blast waves in a solid multicomponent viscoplastic medium. Explosive Affair, 88(45), 28-36.

8. Grigoryan, S.S. (1964). To solution of the task of underground explosion in soft soils. Applied Mathematics and Mechanics, 28(2), 1070-1075.

9. Timoshenko, S. P. (1937). Theory of elasticity. Moscow: ONTI.

10. Lugovoy P. Z., Meish, V. F., \& Remez, N. S. (2000). Elastoplastic behaviour of ribbed cylindrical shells under nonstationary loading. Archives of Civil Engineering, XLVI, 3, 43-49.

\section{SEISMISKO SPRĀDZIENU VIL̦N̦U SIMULĀCIJA AR PAZEMES CAURUL̨U MIJIEDARBĪBU}

Remezs N., Dičko A., Krajčuks S., Ostapčuks N., Jevtejeva L., Bronitskijs V.

Kopsavilkum s

Raksts sniedz skaitlisko simulāciju viļ̧nu procesu mijiedarbībai sistēmā "augsnes masīvs - pazemes caurul̦vads" lādiņa sprādzienā uz zemes virsmas. Simulācija tiek pētīta Timošenko tipa čaulu nelineārās teorijas ietvaros. Augsni modelē cietā porainā daudzkomponentu viskozes-plastmasas vidē. Pētījumā tika noteikti sistēmas stresa-deformācijas stāvokḷa izmaiṇu modeḷi atkarībā no cauruḷvada novietojuma dzilıuma un tā diametra.

26.04.2018. 